\title{
Accelerometry-based gait analysis, an additional objective approach to screen subjects at risk for falling.
}

Citation for published version (APA):

Senden, R., Savelberg, H. H., Grimm, B., Heyligers, I. C., \& Meijer, K. (2012). Accelerometry-based gait analysis, an additional objective approach to screen subjects at risk for falling. Gait \& Posture, 36(2), 296300. https://doi.org/10.1016/j.gaitpost.2012.03.015

Document status and date:

Published: 01/01/2012

DOI:

10.1016/j.gaitpost.2012.03.015

Document Version:

Publisher's PDF, also known as Version of record

\section{Document license:}

Taverne

\section{Please check the document version of this publication:}

- A submitted manuscript is the version of the article upon submission and before peer-review. There can be important differences between the submitted version and the official published version of record.

People interested in the research are advised to contact the author for the final version of the publication, or visit the DOI to the publisher's website.

- The final author version and the galley proof are versions of the publication after peer review.

- The final published version features the final layout of the paper including the volume, issue and page numbers.

Link to publication

\footnotetext{
General rights rights.

- You may freely distribute the URL identifying the publication in the public portal. please follow below link for the End User Agreement:

www.umlib.nl/taverne-license

Take down policy

If you believe that this document breaches copyright please contact us at:

repository@maastrichtuniversity.nl

providing details and we will investigate your claim.
}

Copyright and moral rights for the publications made accessible in the public portal are retained by the authors and/or other copyright owners and it is a condition of accessing publications that users recognise and abide by the legal requirements associated with these

- Users may download and print one copy of any publication from the public portal for the purpose of private study or research.

- You may not further distribute the material or use it for any profit-making activity or commercial gain

If the publication is distributed under the terms of Article $25 \mathrm{fa}$ of the Dutch Copyright Act, indicated by the "Taverne" license above, 


\title{
Accelerometry-based gait analysis, an additional objective approach to screen subjects at risk for falling ${ }^{\text {ir }}$
}

\author{
R. Senden ${ }^{\text {a,b,*, H.H.C.M. Savelberg }}{ }^{\text {b }}$, B. Grimm ${ }^{\text {a }}$, I.C. Heyligers ${ }^{\text {a }}$, K. Meijer ${ }^{\text {b }}$ \\ ${ }^{a}$ Atrium Medical Center, Department of Orthopaedic Surgery E Traumatology, Henri Dunantstraat 5, Heerlen, P.O. Box 4446,6401 CX Heerlen, The Netherlands

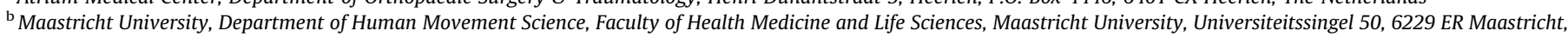 \\ The Netherlands
}

\section{A R T I C L E I N F O}

\section{Article history:}

Received 12 June 2011

Received in revised form 10 March 2012

Accepted 19 March 2012

\section{Keywords:}

Accelerometry-based gait analysis

Tinetti

Fall risk

Elderly

\begin{abstract}
A B S T R A C T
This study investigated whether the Tinetti scale, as a subjective measure for fall risk, is associated with objectively measured gait characteristics. It is studied whether gait parameters are different for groups that are stratified for fall risk using the Tinetti scale. Moreover, the discriminative power of gait parameters to classify elderly according to the Tinetti scale is investigated. Gait of 50 elderly with a Tinneti $>24$ and 50 elderly with a Tinetti $\leq 24$ was analyzed using acceleration-based gait analysis. Validated algorithms were used to derive spatio-temporal gait parameters, harmonic ratio, inter-stride amplitude variability and root mean square (RMS) from the accelerometer data. Clear differences in gait were found between the groups. All gait parameters correlated with the Tinetti scale ( $r$-range: 0.20 0.73). Only walking speed, step length and RMS showed moderate to strong correlations and high discriminative power to classify elderly according to the Tinetti scale. It is concluded that subtle gait changes that have previously been related to fall risk are not captured by the subjective assessment. It is therefore worthwhile to include objective gait assessment in fall risk screening.
\end{abstract}

(c) 2012 Elsevier B.V. All rights reserved.

\section{Introduction}

Falls are the most common accidents in elderly causing serious problems; in addition falls have shown to be the sixth leading cause of death among elderly [1]. Numerous factors have been related to fall risk, including changes in gait [1-4]. Up to $70 \%$ of the falls in elderly occur during walking. Fletcher et al. showed that individuals with an impaired mobility were 1.65 times more likely to experience a fall [5]. Indeed, gait and balance disturbances are shown to be better predictors for imminent falls than other risk factors like for instance impaired vision [6]. Several gait characteristics have been associated with fall risk and fall history, i.e. slow speed, shortened swing phase, increased gait unsteadiness and stride-to-stride variability $[1,3,4,7,8]$.

\footnotetext{
Disclaimer: All authors were fully involved in the study and preparation of the manuscript. The material within has not been and will not be submitted for publication elsewhere.

* Corresponding author at: Atrium Medical Center, Department of Orthopaedic Surgery \& Traumatology, Henri Dunantstraat 5, Heerlen, P.O. Box 4446, 6401 CX Heerlen, The Netherlands. Tel.: +31 0634023131.

E-mail addresses: rach_senden@yahoo.com (R. Senden), hans.savelberg@maastrichtuniversity.nl (H.H.C.M. Savelberg),

b.grimm@atriummc.nl (B. Grimm), i.heyligers@atriummc.nl (I.C. Heyligers), kenneth.meijer@maastrichtuniversity.nl (K. Meijer).
}

Various tools are currently applied in clinical practice to quantify fall risk. At this moment, there is no gold standard. Moreover there is no consistency among clinicians regarding the best tool for assessing fall risk [9]. Some assessments rely on functional measures like timing a physical performance. These tools are mainly sensitive for elderly with an increased fall risk, who have visually detectable deviations in function (e.g. decreased ambulation) [10]. Questionnaire-based checklists evaluating multi-dimensional risk factors such as psychological status (e.g. Physiological Profile Approach (PPA) [11]) showed to be reliable and valid to assess fall risk, but they are not suitable for clinical use where time is limited [11]. Fall history has also frequently been employed as indicator for fall risk. This method is clinically feasible, but lacks reliability especially in subjects who are forgetful [12]. Other commonly used approaches evaluate functional aspects of postural stability by visually observing functional limitations (e.g. Berg Balance Scale) [9]. The Tinetti scale is one of these subjective approaches frequently used and widely accepted in clinical settings to assess mobility dysfunctions in elderly [1315], to assess fall risk in individuals with Parkinson's [16] and Huntington's Disease [17] and to predict falls among healthy elderly subjects $[15,18]$. The response to falls of the Tinetti-balance subscore is only moderate (Area Under Curve, AUC 0.6), but similar and even higher than the predictive power of functional measures like the Timed Get Up \& Go (AUC 0.6), functional reach (AUC 0.5) and one-leg stance (AUC 0.5) test [15]. This suggests that 
combining a subjective and a functional measure may be of added value for fall risk assessment. Since objectively measured gait characteristics have been associated with fall risk $[1,3,4,7,8]$ and because gait analysis provides more detailed information about the functional ability of individuals than commonly used functional measures (e.g. Get Up and Go), objective gait analysis is indicated as an obvious functional measure.

Acceleration-based gait analysis (AGA) has become popular in clinical practice. Accelerometers have been applied to objectively, reliably and reproducibly analyze gait in different populations [2,19-22], to identify fear of falling and to differentiate fallers from non-fallers [5,23]. In addition the acceleration pattern of the pelvis during walking has been associated with physiological falls risk as measured by the comprehensive PPA [4]. Direct relationships between objectively measured gait characteristics as measured by AGA and commonly used subjective scales for fall risk, like the Tinetti scale, are currently missing. It is in addition unknown whether objectively measured gait characteristics are of additional value in current fall risk screening.

This study investigated whether the Tinetti scale, as a subjective measure for fall risk, is associated with objectively measured gait characteristics related to fall risk. Specifically, it was studied whether AGA-parameters are different for groups that are stratified for fall risk using the Tinetti scale. Moreover, the discriminative power of AGA-parameters to classify elderly according to the Tinetti scale was investigated.

\section{Methods}

\subsection{Subjects}

One hundred subjects of which 50 without (avg. $74 \pm 5$ years) and 50 with a fall risk (avg. $79 \pm 6$ years) were included in this case control study (Table 1). The inclusion criteria were: age of 65 years or older, able to walk without assistive devices and no severe cognitive impairments. All subjects were informed about the study and gave written informed consent. Ethics approval was obtained from the local ethical committee.

\subsection{Fall risk}

The Tinetti scale was used as an indicator of fall risk [18] which is based on visual gait and balance assessment. A total score of 24 points or less out of 28 indicates fall risk [18]. This test was performed by two researchers trained in the assessment. It took roughly $15-20 \mathrm{~min}$ to complete the test. The risk group was further divided into a low (Tinetti 19-24/28, $n=31$ ) and high (Tinetti $<19 / 28$, $n=19$ ) risk group.

\subsection{Test procedure}

Fall history and subject demographics were collected (Tables 1 and 2). Fall history was obtained by asking the subjects whether they have fallen in the last six months. Falls were defined as unintentionally coming to rest on the ground. All

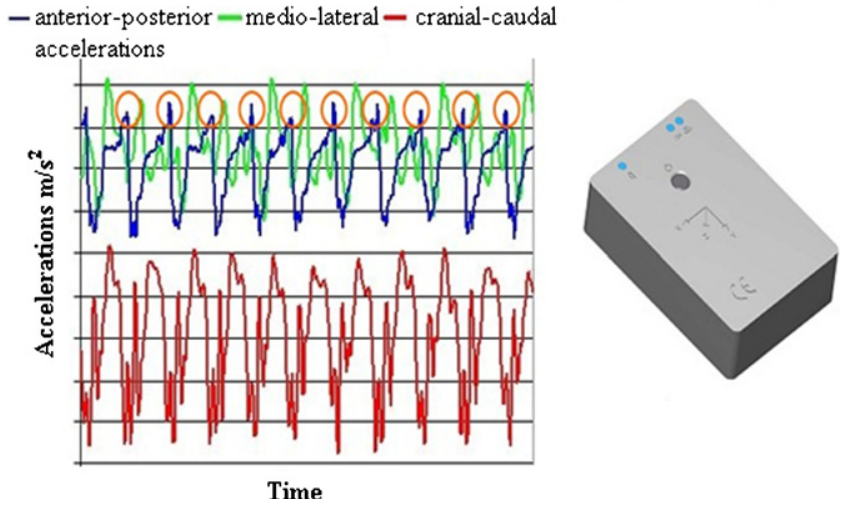

Fig. 1. 3D acceleration signal of the gait pattern measured by the accelerometer (DAAFb, right). Gait parameters are derived using a 'template' peak detection algorithm which relies on the anterior-posterior acceleration signal (blue signal). The 'o' represents the peak that is detected, which corresponds with foot contact. (For interpretation of the references to color in this figure legend, the reader is referred to the web version of the article.)

subjects performed a walking test while a triaxial accelerometer (DAAFb, $f 102 \mathrm{~Hz}$ or ETB-Pegasus, $f 100 \mathrm{~Hz}$, Fig. 1) was attached to the level of the sacrum using double sided tape. Subjects walked a $20 \mathrm{~m}$ straight distance in a hospital corridor at preferred speed. Their last step had to take them beyond the $20 \mathrm{~m}$ mark. The additional distance was measured by a ruler to obtain the exact distance walked. After $20 \mathrm{~m}$ subjects turned around and walked back. This procedure was carried out three times, resulting in six walking trials. The duration of the test set-up ( $\pm 1 \mathrm{~min}$ ) and measurement $( \pm 3 \mathrm{~min}$ ) is more or less $4 \mathrm{~min}$. The analysis of the data takes \pm 5 $10 \mathrm{~min}$. The data analysis relied on semi-automated algorithms requiring some manual intervention (e.g. check for correct peaks, indicate start and stop point) [19].

\subsection{Gait parameters}

A self-designed template algorithm was applied on the anterior-posterior acceleration signal to identify specific peaks corresponding to foot contact as is shown by Zijlstra. A pilot study, revealed good agreement between our template algorithm and a manual peak detection algorithms according to Zijlstra et al. In this way, steps were recognized and gait parameters were derived (Fig. 1) [24]. Spatiotemporal parameters like number of steps (amount peaks), walking speed (distance/walking time), cadence (number of steps/walking time), step time (time from foot contact to foot contact) and step length (distance/number of steps) were determined. The step time asymmetry was calculated to indicate differences between left and right leg movements [22]. The harmonic ratio, inter-stride amplitude variability and root mean square (RMS), all relying on vertical acceleration signal, were determined as defined and described by Menz et al. [25]. The average of gait parameters measured over six trials was used for analysis.

\subsection{Statistical analysis}

ANOVA was used to examine differences in AGA-parameters between groups (Tinetti $>24$ vs. $19-24$ vs. <19). Differences in fall history were studied by Fisher's

Table 1

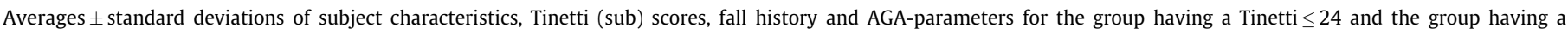
Tinetti $>24$.

\begin{tabular}{|c|c|c|c|}
\hline & Tinetti $\leq 24(n=50)$ & Tinetti $>24(n=50)$ & $p$-values \\
\hline Gender (F/M) & $23 / 27$ & $33 / 17$ & 0.07 \\
\hline Age (years) & $74.2 \pm 5.1$ & $78.9 \pm 6.2$ & $<0.01^{*}$ \\
\hline Height (m) & $1.68 \pm 0.09$ & $1.67 \pm 0.11$ & 0.51 \\
\hline Weight (kg) & $72.3 \pm 12.7$ & $70.3 \pm 13.5$ & 0.44 \\
\hline BMI $\left(\mathrm{kg} / \mathrm{m}^{2}\right)$ & $25.47 \pm 3.76$ & $25.10 \pm 4.14$ & 0.64 \\
\hline Tinetti total & $26.5 \pm 1.4$ & $20.0 \pm 3.4$ & $<0.01^{*}$ \\
\hline Tinetti gait & $11.7 \pm 0.6$ & $9.0 \pm 1.7$ & $<0.01^{*}$ \\
\hline Tinetti balance & $14.9 \pm 1.2$ & $11.0 \pm 2.4$ & $<0.01^{*}$ \\
\hline Fall history & $24 / 50$ & $12 / 50$ & $0.02^{*}$ \\
\hline Walking speed $(\mathrm{m} / \mathrm{s})$ & $1.23 \pm 0.22$ & $0.86 \pm 0.26$ & $<0.01^{*}$ \\
\hline Frequency (steps/s) & $1.86 \pm 0.17$ & $1.69 \pm 0.23$ & $<0.01^{*}$ \\
\hline Step length $(\mathrm{m})$ & $0.66 \pm 0.09$ & $0.51 \pm 0.13$ & $<0.01^{*}$ \\
\hline Asymmetry (\%) & $6.05 \pm 5.55$ & $9.24 \pm 7.06$ & $0.02^{*}$ \\
\hline Root mean square (vertical accelerations) & $0.25 \pm 0.07$ & $0.16 \pm 0.07$ & $<0.01^{*}$ \\
\hline Inter-stride amplitude variability (vertical accelerations) & $0.08 \pm 0.03$ & $0.07 \pm 0.03$ & $<0.01^{*}$ \\
\hline Harmonic ratio (vertical accelerations) & $3.09 \pm 1.25$ & $2.18 \pm 1.09$ & $<0.01^{*}$ \\
\hline
\end{tabular}

" Significant difference $(p<0.05)$ between groups; Tinetti $\leq 24$ indicates at risk for falling, Tinetti $>24$ indicates no fall risk. 
exact test. Pearson correlation was performed to investigate associations between the Tinetti scale, AGA-parameters, fall history and subject demographics. Linear regression analysis was done to further explore associations between AGAparameters and the Tinetti scale, taking fall history and subject demographics into account. The discriminative power of AGA to differentiate subjects with a Tinetti $\leq 24$ and $>24$ was assessed by determining the area under the Receiver Operating Characteristic (ROC) curve. The area under the curve (AUC), including $95 \%$ confidence intervals, was used as a measure of the overall performance of a diagnostic test. The closer AUC is to one, the better the overall diagnostic performance of the test [26]. All analyses were done in SPSS 15.0. A $p$-value $\leq 0.05$ was considered significant.

\section{Results}

The group with a Tinetti $\leq 24$ was significantly older and more often reported a fall in the six months prior to the experiment. The groups were similar in weight and height (Tables 1 and 2). The group with a Tinetti $\leq 24$ walked significantly slower, with shorter steps and lower step frequency than the group with a Tinetti $>24$. Moreover smaller RMS, larger step time asymmetry, lower harmonic ratio and smaller inter-stride amplitude variability was found in the group with a Tinetti $\leq 24$ (Table 1 ). Comparable differences were found between risk groups with exception of the step frequency, step time asymmetry and inter-stride amplitude variability which were comparable between these groups (Table 2).

All gait parameters correlated significantly with the Tinetti scale. The strongest correlations occurred for walking speed, step length and RMS (resp. $r=0.73, r=0.71, r=0.60, p<0.01, p<0.05$ ) and the poorest for step time asymmetry $(r=-0.20, p=0.05)$. Walking speed, step length, RMS, step frequency, inter-stride amplitude variability and harmonic ratio correlated positively with the Tinetti scale (Fig. 2). A negative correlation was found with step time asymmetry (Table 3 ). Age correlated moderately $(r=-0.59, p<0.01)$ and fall history weakly $(r=-0.22, p=0.03)$ with the Tinetti scale, while no correlation was found between the Tinetti scale and height $(p=0.17)$, weight $(p=0.27)$. Poor to excellent correlations were observed between AGA-parameters $(r$ range: -0.20 (RMS vs. step time asymmetry) to 0.91 (RMS vs. walking speed), $p<0.05)$.

AGA-parameters (except asymmetry and inter-stride amplitude variability) correlated with age, showing the lowest correlation for RMS $(r=0.38, p<0.01)$ and the highest correlation for walking speed $(r=0.55, p<0.01)$. Step time asymmetry was the only AGA-parameter correlating with fall history, showing a weak correlation $(r=0.25, p=0.01)$.

ROC analysis showed that walking speed, step length and RMS have excellent discriminative power to differentiate subjects with different Tinetti scores showing AUC ranging from 0.81 to 0.85 . Acceptable discriminative power was found for step frequency,
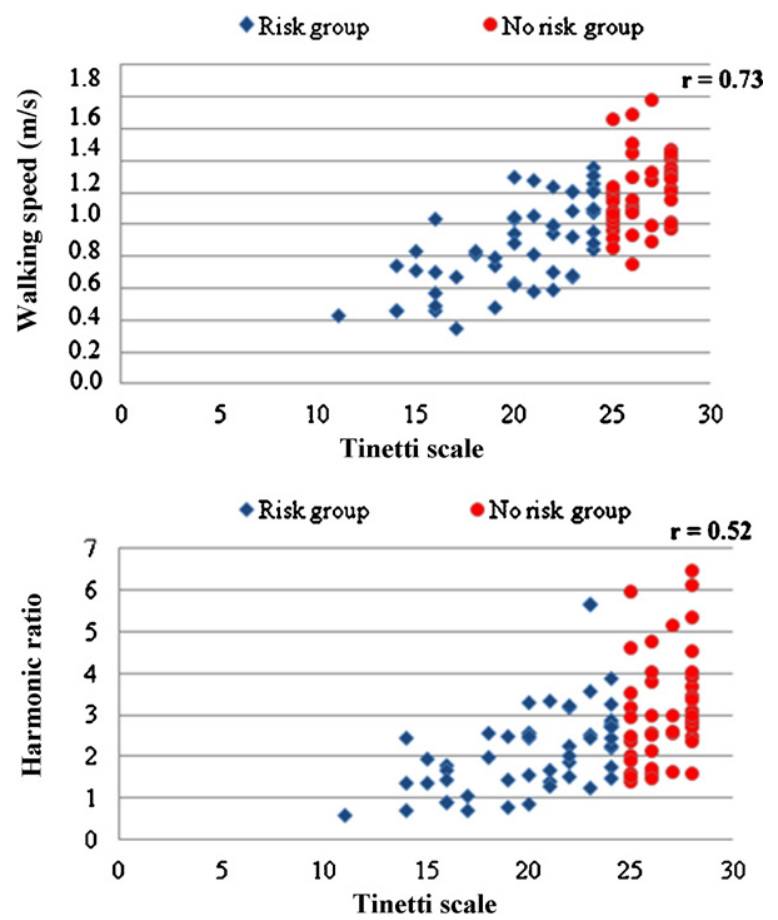

Fig. 2. Correlation plot Tinetti scale vs. walking speed (top) and harmonic ratio (bottom).

harmonic ratio and inter-stride amplitude variability (AUC range: $0.71-0.73$ ). Poor discriminative power (AUC $=0.67$ ) was found for asymmetry.

\section{Discussion}

This study investigated whether the Tinetti scale, as a commonly used subjective measure for fall risk, is associated with objectively measured gait characteristics. Clear differences in gait were found between the groups with different Tinetti scores. Walking speed, step length and RMS were the only AGAparameters showing a strong association with the Tinetti scale. These parameters had also the best discriminative power to classify elderly according to the Tinetti scale.

The observed differences in AGA-parameters between groups were similar to previous studies that classified fall risk based on the PPA $[1,4]$ or Tinetti scale combined with fall history and functional measures [2]. The slower walking speed and shorter steps in elderly with a Tinetti $\leq 24$ indicate that they adopt a more

Table 2

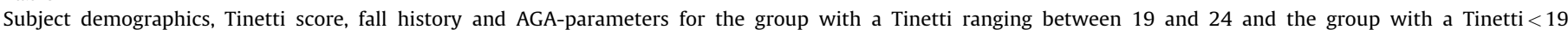
(average \pm standard deviation).

\begin{tabular}{|c|c|c|c|}
\hline & Tinetti $19-24(n=31)$ & Tinetti $<19(n=19)$ & $p$-values \\
\hline Age (years) & $76.0 \pm 4.8$ & $83.6 \pm 5.3$ & $<0.01^{*}$ \\
\hline Height (m) & $1.69 \pm 0.09$ & $1.65 \pm 0.13$ & 0.19 \\
\hline Weight (kg) & $72.9 \pm 14.1$ & $66.2 \pm 11.7$ & 0.08 \\
\hline Tinetti & $21.9 \pm 1.7$ & $17.0 \pm 3.3$ & $<0.01^{*}$ \\
\hline Fall history & $17 / 31$ & $7 / 19$ & 0.25 \\
\hline Walking speed $(\mathrm{m} / \mathrm{s})$ & $0.95 \pm 0.24$ & $0.72 \pm 0.26$ & $<0.01^{*}$ \\
\hline Frequency (steps/s) & $1.71 \pm 0.20$ & $1.64 \pm 0.28$ & 0.27 \\
\hline Step length $(\mathrm{m})$ & $0.55 \pm 0.11$ & $0.43 \pm 0.11$ & $0.01^{*}$ \\
\hline Asymmetry (\%) & $9.39 \pm 8.14$ & $8.99 \pm 5.03$ & 0.84 \\
\hline Root mean square (vertical accelerations) & $0.18 \pm 0.07$ & $0.13 \pm 0.07$ & $0.03^{*}$ \\
\hline Inter-stride amplitude variability (vertical accelerations) & $0.07 \pm 0.03$ & $0.06 \pm 0.02$ & 0.21 \\
\hline Harmonic ratio (vertical accelerations) & $2.51 \pm 1.13$ & $1.64 \pm 0.77$ & $0.01^{*}$ \\
\hline
\end{tabular}

\footnotetext{
Significant difference $(p<0.05)$ between groups; Tinetti 19-24 indicates low fall risk, Tinetti $<19$ indicates high fall risk.
} 
Table 3

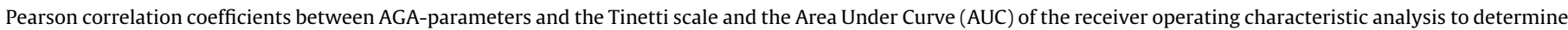
the discriminative power of AGA to differentiate elderly with a Tinetti $\leq 24$ from the elderly with a Tinetti $>24$.

\begin{tabular}{|c|c|c|c|}
\hline & Correlation coefficient & AUC & 95\% confidence interva \\
\hline Walking speed $(\mathrm{m} / \mathrm{s})$ & $\begin{array}{l}0.73^{*} \\
p<0.01\end{array}$ & 0.85 & $0.77-0.92$ \\
\hline Frequency (steps/s) & $\begin{array}{l}0.49^{*} \\
p<0.01\end{array}$ & 0.74 & $0.64-0.84$ \\
\hline Step length (m) & $\begin{array}{l}0.71^{*} \\
p<0.01\end{array}$ & 0.83 & $0.75-0.91$ \\
\hline Asymmetry (\%) & $\begin{array}{l}-0.20^{*} \\
p=0.01\end{array}$ & 0.67 & $0.63-0.83$ \\
\hline Root mean square (vertical accelerations) & $\begin{array}{l}0.60^{*} \\
p<0.01\end{array}$ & 0.81 & $0.73-0.89$ \\
\hline Harmonic ratio (vertical accelerations) & $\begin{array}{l}0.52^{*} \\
p<0.01\end{array}$ & 0.73 & $0.64-0.83$ \\
\hline Inter-stride amplitude variability (vertical accelerations) & $\begin{array}{l}0.33^{*} \\
p=0.01\end{array}$ & 0.71 & $0.61-0.81$ \\
\hline
\end{tabular}

Significant correlation $(p<0.05)$.

cautious gait pattern possibly to minimize upper body displacements $[4,27,28]$. Moreover this group showed impaired interstride amplitude variability, RMS and harmonic ratio, implying e.g. that elderly with a Tinetti $\leq 24$ have more difficulty in controlling gait smoothness and that their gait pattern is more variable [4].

All AGA-parameters correlated with the Tinetti scale. However only walking speed and step length, which are highly correlated $(r>0.9, p<0.01)$, were both strongly associated with the Tinetti scale $(r>0.7, p<0.01)$. A faster walking speed was related to higher Tinetti scores, which corresponds to previous studies relating a slow walking speed with an increased fall risk $[2,4,29]$. Moreover walking speed and step length were the most powerful AGA-parameters to classify elderly according to the Tinetti scale (resp. AUC 85\% and 83\%). The coordinates of the ROC curve of the walking speed showed that a cut-off level of $1.08 \mathrm{~m} / \mathrm{s}(3.89 \mathrm{~km} / \mathrm{h})$ is able to discriminate the group with a Tinetti $\leq 24$ from the group with a Tinetti $>24$ (76\% sensitivity, 70\% specificity). This cut-off value corresponds well with the study of Bautmans et al. (cut-off $1.16 \mathrm{~m} / \mathrm{s}$, sensitivity $78 \%$, specificity $78 \%$ ), which also demonstrated that walking speed has the best discriminative capacity to classify elderly according to fall risk as measured by fall history, Tinetti and timed-get-up-and-go test [2]. RMS showed also good discriminative power to differentiate groups of elderly with different Tinetti scores (AUC 81\%). This parameter is highly correlated with the walking speed $(r=0.91, p<0.01)$ indicating redundancy [4]. RMS is a useful proxy for the walking speed as it can be derived directly from the accelerometer data, not requiring additional measurements (e.g. distance) and calculations.

Many of the differences in AGA-parameters between groups appear to be related to differences in walking speed as is shown by their correlations $(r$-range -0.25 to $0.93, p<0.0$ ). Consequently, harmonic ratio and inter-stride variability had no real additional value (AUC $<0.74, r<0.6, p<0.01$ ) to distinguish between the groups. These parameters may become more powerful and discriminative for other populations having more complex limitations like Parkinson Disease patients [30]. This however needs further investigation and requires a reference database including norm values for AGA-parameters which may allow to identify fall risk-related gait characteristics in various population groups [22].

There was a small but significant difference in age between the risk groups and it could be argued that the gait differences are simply a consequence of age. It is known that gait changes with advancing age due to factors such as a loss in strength. However comparing AGA-parameters between the younger (65-74 years) and older (75-84 years) subjects of each group, showed that the gait differences between the age groups were bigger in the group with a Tinetti $\leq 24$ than in the group with a Tinetti $>24$. This suggests that age is a factor, particularly in the group with a Tinetti $\leq 24$. However this needs further investigation including a larger amount of subjects per age (young vs. old) and fall risk group.

Linear regression analysis showed that only walking speed, step length and RMS are significant determinants of the Tinetti scale, with fall history and age only having small additional effects. Harmonic ratio and inter-stride amplitude variability had no additional value. The two best models, including speed $(B=7.76)$, age $(B=-0.19)$ and fall history $(B=-1.28)$ or RMS $(B=21.50)$, age $(B=-0.29)$ and fall history $(B=1.40)$ were able to explain respectively $60 \%$ and $52 \%$ of the variability in Tinetti scale. Analysis with fall history as an indicator for fall risk (logistic regression analysis) did not lead to better results $\left(R^{2}=0.09\right.$, with step time asymmetry as significant variable).

Interestingly, inter-stride amplitude variability and harmonic ratio which are frequently considered indicators for an elevated fall risk, had only moderate to poor associations with the Tinetti scale and were not incorporated in the regression models. Several aspects may explain the relatively poor association between the subjective and objective gait assessment. First of all, the population was categorized in two groups in advance (Tinetti $\leq$ and $>24$ ). In future studies, preferable prospective cross-sectional studies, a random inclusion of many elderly of varying subject characteristics and of varying Tinetti scores may provide further insight into these associations. However, in general the data was equally distributed over the studied ranges. Secondly, AGA-parameters were compared to the full Tinetti scale, which also includes a balance assessment (involves 57\% of the Tinetti score). However, performing the analysis with the Tinetti-gait sub-score did not improve the observed associations (results not shown). It can be concluded that the subtleties in gait that have previously been shown to be related to fall risk are not captured by the subjective assessment $[1,3,4,7]$. Hence, it may be worthwhile to include objective gait monitoring in fall risk screening [2].

This is one of the few studies that has included a large group ( $n=100)$ of representative older subjects who had an average age of $77 \pm 6$ years (range 65-90 years) and are categorized for fall risk using the Tinetti scale. However, a more comprehensive fall risk screening may be required to better understand the contribution of gait monitoring to fall risk assessment. One of the issues in crosssectional fall risk studies is that there is not a real gold standard to quantify fall risk. Fall risk is a multi-factorial problem [11] and several aspects (e.g. medication use or fall history) were disregarded in this study. Interestingly, fall history, which is commonly used as an indicator of fall risk $[2,12]$ appeared to have only a small added values 
in this study. Screening various fall risk related aspects (e.g. Physiological Profile Assessment [11], fall history and gait assessment) in combination with a prospective evaluation of fall accidents (e.g. by fall detectors) [12] may strengthen a future study.

The findings of this study demonstrate the potential of AGA as objective gait analysis system in elderly at risk for falling. Detailed and objective information about changes and deviations in gait can be achieved by AGA. The practical properties of AGA (fast, easy, portable, approaching daily life conditions) will allow its use in clinical practice (e.g. nursing homes) in the future. Fall risk related AGA-parameters may yield targets for fall prevention programs. Moreover AGA may help to make decisions regarding fall prevention and may allow to evaluate, optimize and develop fall prevention programs (e.g. Tai Chi). However currently there is no evidence that the Tinetti scale should be replaced by AGA, neither that fall risk assessment should rely on AGA. Future, preferably prospective studies are needed to indicate the most important and predictive variables for fall risk. The results of the current study will be the basis for these studies.

\section{Conclusion}

Subtleties in gait that have previously been related to fall risk are not captured by the subjective fall risk assessment. It is therefore worthwhile to include objective gait assessment in fall risk screening.

\section{Acknowledgments}

This study was not sponsored. The study design, the data collection, the analysis and interpretation of data and the writing of the manuscript were done independently.

\section{Conflict of interest statement}

None of the authors had financial and personal relationships with other people or organizations that could inappropriately influence their work.

\section{References}

[1] Verghese J, Holtzer R, Lipton RB, Wang C. Quantitative gait markers and incident fall risk in older adults. J Gerontol A Biol Sci Med Sci 2009;64A(8):896-901.

[2] Bautmans I, Jansen B, Keymolen van B, Mets T. Reliability and clinical correlates of 3D-accelerometry based gait analysis outcomes according to age and fall-risk. Gait Posture 2011;33(3):366-72.

[3] Lamoth CJ, Deudekom van FJ, Campen van JP, Appels BA, Vris de OJ, Pijnappels M. Gait stability and variability measures show effects of impaired cognition and dual tasking in frail people. J Neuroeng Rehabil 2011;8:2-10.

[4] Menz HB, Lord SR, Fitzpatrick RC. Acceleration patterns of the head and pelvis when walking are associated with risk of falling in community-dwelling older people. J Gerontol 2003;58a:446-52.

[5] Fletcher PC, Hirdes JP. Risk factors for falling among community-based seniors using home care services. J Gerontol Med Sci 2002;57A(8):M504-10.
[6] Ganz DA, Bao Y, Shekelle PG, Rubenstein LZ. Will my patient fall? JAMA 2007;297:77-86.

[7] Hausdorff JM, Edelberg HE, Mitchell SL, GOldberger AL, Wei JY. Increased gait unsteadiness in community dwelling elderly fallers. Arch Phys Med Rehabil 1997;78:278-83.

[8] Brach JS, Berlin JE, VanSwearingen JM, Newman AB, Studenski SA. Too much or too little step width variability is associated with a fall history in older persons who walk at or near normal gait speed. J Neuroeng Rehabil 2005;2:20-8.

[9] Tiedemann A, Shimada H, Sherrington C, Murray S, Lord S. The comparative ability of eight functional mobility tests for predicting falls in communitydwelling older people. Age Ageing 2008;37:430-5.

[10] Podsiadlo D, Richardson S. The timed up \& go: a test of basic functional mobility for frail eldelry persons. J Am Geriatr Soc 1991;39:142-8.

[11] Lord SR, Menz HB, Tiedemann A. A physiological profile approach to falls risk assessment and prevention. Phys Ther 2003;83(3):237-52.

[12] Ganz DA, Higashi T, Rubenstein LZ. Monitoring falls in cohort studies of community-dwelling older people: effect of the recall interval. J Am Geriatr Soc 2005;53:2190-4.

[13] Raîche M, Hebert R, Prince F, Corriveau H. Screening older adults at risk of falling with the Tinetti balance scale. Lancet 2000;356:1001-2.

[14] Sterke CS, Huisman SL, Beeck van EF, Looman CWN, Cammen van der RJM. Is the Tinetti performance oriented mobility assessment (POMA) a feasible and valid predictor of short-term fall risk in nursing home residents with dementia? Int Psychogeriatr 2010;22(2):254-63.

[15] Lin MR, Hwang HF, Hu MH, Isaac HD, Wang YW, Huang FC. Psychometric comparisons of the timed up and go, one-leg stand, functional reach and Tinetti balance measures in community-dwelling older people. J Am Geriatr Soc 2004;52:1343-8.

[16] Bloem BR, Hasudorff JM, Visser JE, Giladi N. Falls and freezing of gait in Parkinson's disease: a review of two interconnected, episodic phenomena. Mov Disord 2004;19:871-84.

[17] Kloos A, Kegelmeyer DA, Young GS, Kostyk SK. Fall risk assessment using the tinetti mobility test in individuals with Hungtington's disease. Mov Disord 2010;25(16):2838-44.

[18] Tinetti ME. Performance-oriented assessment of mobility problems in elderly patients. J Am Geriatr Soc 1986;34:119-26.

[19] Senden R, Grimm B, Heyligers IC, Savelberg HHCM, Meijer K. An accelerationbased gait test for healthy subjects: reliability and reference data. Gait Posture 2009;30(2):192-6.

[20] Senden R, Heyligers IC, Meijer K, Savelberg HHCM, Grimm B. Accelerationbased motion analysis as a tool for rehabilitation: exploration in simulated functional knee limited walking conditions. Am J Phys Med Rehab 2010;90(3):226-32.

[21] Hartmann A, Luzi S, Murer K, de Bie RA, de Bruin ED. Concurrent validity of a trunk tri-axial accelerometer system for gait analysis in older adults. Gait Posture 2009;29:444-8.

[22] Senden R, Grimm B, Meijer K, Savelberg H, Heyligers IC. The importance to including objective functional outcomes in the clinical follow up of total knee arthroplasty patients. The Knee 2010;18(5):306-11.

[23] Gietzelt M, Nemitz G, Wolf K, Schwabedissen H, Haux R, Marschollek M. A clinical study to assess fall risk using a single waist accelerometer. Inform Health Social Care 2009;34(4):181-8.

[24] Zijlstra W, Hof AL. Assessment of spatio-temporal gait parameters from trunk accelerations during human walking. Gait Posture 2003;18(2):1-10.

[25] Menz HB, Lord SR, Fitzpatrick RC. Acceleration patterns of the head and pelvis when walking on level and irregular surfaces. Gait Posture 2003;18(1):35-46.

[26] Hosmer MJ, Bosscher RJ, Wieringen van PCW, editors. Applied logistic regression. Chichester: Wiley; 2000.

[27] Nutt JG. Classification of gait and balance disorders. Adv Neurol 2001;87:13541.

[28] Gehlesen GM, Whaley MH. Gait assessment in the elderly: a gait abnormality rating scale and its relation to falls. J Gerontol Med Sci 1990;45:M12-9.

[29] Kegelmeyer DA, Kloos AD, Thomas KR, Kostyk SK. Reliability and validity of the tinetti mobility test for Individuals with Parkinson disease. Phys Ther 2007:87(10):1369-78.

[30] Latt MD, Menz HB, Funcg VS, Lord SR. Acceleration patterns o th head and pelvis during gait in older people with parkinson's disease: a comparison of fallers and nonfallers. J Gerontol 2009;64A(6):700-6. 